\title{
HUBUNGAN ANGKAT ANGKUT PASIEN DENGAN KELUHAN MUSCULOSKELETAL DISORDERS (MSD'S) PADA PERAWAT RUANG RAWAT INAP RSUD TELUK KUANTAN TAHUN 2018
}

\section{THE CORRELATION BETWEEN PATIENT LIFTING WITH MUSCULOSKELETAL DISORDERS (MSD'S) COMPLAINT ON INPATIENT ROOM NURSES AT TELUK KUANTAN GENERAL HOSPITAL 2018}

\author{
Sri Eka Putri', Tjipto Suwandi², Makomulamin² \\ ${ }^{1}$ Program Studi Magister Kesehatan Masyarakat \\ ${ }^{2}$ STIKes Hang Tuah Pekanbaru \\ Email: Sriekaputri95@gmail.com
}

\begin{abstract}
Musculosceletal complaints are a complaint on the skeletal muscle sections felt by a person starting from a very mild to very painful complaint. If the muscles receive static loads repeatedly and over a long period of time, they can cause complaints of joints, ligaments and tendons. The purpose of this study was to determine the correlation between job factors (work postur of patient lifting and load weight) and individual factors (age, body mass index (BMI), exercise habits and working period) with musculosceletal disorders (MSD's) complaint on inpatient room nurses at Teluk Kuantan General Hospital. The type of research is a quantitative using method observasional analytic with cross sectional study design. Research was conducted on June-July 2018. In this study a sample of 56 nurses inpatient rooms at Teluk Kuantan General Hospital, all nurses were used as research samples. Data was analyzed by univariate, bivariate, and multivariate. The result of this research was $66,1 \%$ proportion of musculosceletal disorders complaining. Variables related to musculoskeletal complaints are work posture and working period. Confounding variables are weight and age. Unrelated variables are body mass index and exercise habits. The conclusion of this study is that the work period is the most dominant variable influencing musculoskeletal disorders with (p-value=0,007; OR: 17,949; 95\% CI: 2,212-145,619). It is recommended for nurses to pay attention to the correct way of lifting patients so that they can adjust to body posture, and for K3RS should more active in providing training related to ergonomic patient handling.
\end{abstract}

Keywords : Musculosceletal disorders, patient lifting, nurses 


\begin{abstract}
Abstrak
Keluhan musculoskeletal adalah keluhan pada bagian-bagian otot skeletal yang dirasakan oleh seseorang dimulai dari keluhan sangat ringan sampai sangat sakit. apabila otot menerima beban statis secara berulang dan dalam waktu yang lama, dan dapat menyebabkan keluhan berupa kerusakan pada sendi, ligament, dan tendon. Tujuan penelitian adalah untuk mengetahui hubungan faktor pekerjaan (postur kerja angkat angkut pasien dan berat beban), faktor individu (Umur, indeks massa tubuh (IMT), kebiasaan olahraga dan masa kerja) dengan keluhan musculoskeletal disorders pada perawat ruang rawat inap RSUD Teluk Kuantan. Jenis penelitian adalah kuantitatif menggunakan metode analitik observasional, dengan menggunakan desain studi penampang analitik. Penelitian dilakukan pada bulan Juni - Juli 2018. Pada penelitian ini sampel berjumlah 56 perawat ruang rawat inap RSUD Teluk Kuantan, seluruh perawat dijadikan sampel penelitian. Analisis data dilakukan secara univariat, bivariat, dan multivariat. Hasil penelitian diperoleh proporsi keluhan musculoskeletal disorders pada perawat ruang rawat inap RSUD Teluk kuantan adalah $66,1 \%$. Variabel yang berhubungan dengan keluhan musculoskeletal disorders adalah postur kerja dan masa kerja. Variabel confounding adalah berat beban dan umur. Variabel yang tidak berhubungan adalah indeks massa tubuh dan kebiasaan olahraga. Kesimpulan dari penelitian ini adalah masa kerja merupakan variabel yang paling dominan berpengaruh terhadap keluhan musculoskeletal disorders dengan (p-value $=0,007$; OR: 17,949; 95\% CI: 2,212-145,619). Disarankan kepada perawat untuk memperhatikan cara angkat pasien yang benar agar bisa menyesuaikan dengan postur tubuh, dan untuk K3RS harus lebih aktif memberikan pelatihan yang berkaitan dengan penanganan pasien yang ergonomis.
\end{abstract}

Kata kunci : Musculoskeletal disorders, angkat angkut pasien, perawat.

\section{PENDAHULUAN}

Keluhan muskuloskeletal adalah keluhan yang dirasakan pada bagian otot rangka seseorang mulai dari keluhan sangat ringan sampai sangat sakit. ketika otot menerima beban statis secara berulang dan dalam jangka waktu yang lama, dapat menyebabkan keluhan berupa kerusakan pada sendi, ligamen dan tendon. Keluhan hingga kerusakan inilah yang biasanya diistilahkan dengan keluhan muskuloskeletal disorders (MSD's). Sebuah metode semi-kuantitatif yang mengevaluasi potensi terjadinya lelah otot pada sebagian besar bagian tubuh melalui penilaian berdasarkan tingkat usaha suatu pekerjaan. Bila terjadi kelelahan otot, maka cedera akan lebih mudah terjadi, bagian tubuh yang berpotensi mengalami lelah otot dikelompokkan menjadi low, moderate dan high sehingga dapat teridentifikasi prioritas penanganan untuk menghindari cedera otot (Tarwaka, 2015).

Menurut hasil laporan labour force survey (2016) prevalensi kasus keluhan muskuloskeletal disorders pada tahun 2015/2016 adalah 539.000 atau sekitar $41 \%$ dari total 1.311 .000 untuk semua penyakit yang berhubungan dengan pekerjaan, dan kasus baru untuk keluhan musculoskeletal disorders tahun 2015/2016 adalah 176.000, dengan ratarata 550 kasus per 100.000 orang. Diperkirakan sekitar 8,8 juta hari kerja hilang disebabkan oleh musculoskeletal disorders dengan rata-rata 16 hari kerja hilang untuk setiap kasusnya dan musculoskeletal disorders menyumbang sekitar 34\% dari semua hari kerja yang hilang yang disebabkan oleh penyakit akibat kerja

Occupational safety and health Administration (OSHA) menyatakan 
bahwa pada tahun 2011, rumah sakit di Amerika Serikat melaporkan rata-rata 6.8 penyakit dan cedera yang berkaitan dengan pekerjaan per 100 karyawan penuh waktu, Ketika cedera yang menyebabkan karyawan kehilangan pekerjaan lebih tinggi pada pekerja di rumah sakit yaitu perawat dibandingkan dengan pekerja bidang konstruksi. Sekitar $48 \%$ dari cedera yang dilaporkan adalah hasil dari "kelelahan dan reaksi tubuh," dan 54\% dari sakit disebabkan oleh keluhan musculoskeletal. Salah satu penyebab terbesar dari cedera ini adalah teknik dalam mengangkat pasien yang tidak tepat (OSHA 3182, 2013).

Di Indonesia dilaporkan bahwa selama kurun waktu 5 tahun terakhir kasus kecelakaan kerja meningkat, dari 96.314 kasus kecelakaan kerja di tahun 2009, meningkat mencapai 103.285 kasus kecelakaan kerja di tahun 2013. BPJS ketenagakerjaan mencatat di Indonesia tidak kurang dari 9 orang meninggal dunia akibat kecelakaan di tempat kerja setiap hari, oleh karena itu diperlukan upayaupaya untuk mencegah terjadinya kecelakaan kerja dan penyakit akibat kerja (ILO, 2013).

Salah satu pekerja yang berisiko mengalami keluhan musculoskeletal disorders di rumah sakit adalah perawat. Tugas yang dilakukan perawat sangat bervariasi, antara lain mengangkat dan mendorong dalam hal penanganan pasien. Gangguan musculoskeletal merupakan satu masalah penting dalam industri rumah sakit dan merupakan gangguan paling banyak diderita perawat. Penyakit akibat kerja yang umum terjadi adalah low back pain terutama diakibatkan oleh kegiatan angkat-angkut pasien, seorang perawat yang mengalami low back pain akan terganggu produktivitas kerjanya.
Produktivitas kerja yang menurun pada akhirnya akan berdampak pada kualitas pelayanan pasien (Nuryaningtyas dkk, 2014).

Hasil prasurvei tahun 2012 di beberapa rumah sakit di Jakarta memperlihatkan, perawat di rumah sakit yang paling banyak melakukan pekerjaan angkat-angkut pasien adalah di unit kerja yang memberikan pelayanan 24 jam yaitu di ruang rawat inap dan di unit gawat darurat. Dari hasil penelitian didapatkan nilai skor REBA 11 yang mana tingkat risiko ergonominya sangat tinggi dan tingkat keluhan musculoskeletal disorders (MSD's) sebesar 80\% pada aktivitas perawat yang melakukan pekerjaan mengangkat dan memindahkan pasien (Kurniawidjaja dkk, 2013). Prevalensi keluhan musculoskeletal disorders yang paling banyak ditemukan adalah pada perawat yang memiliki usia lebih tua, faktor fisik mengangkat dan mendorong pasien, posisi kerja yang tidak ergonomis dalam durasi waktu yang lama, obesitas, masa kerja yang lama, kebiasaan merokok serta kebiasaan olahraga (Rossa dkk, 2017).

Rumah Sakit Umum Daerah (RSUD) Taluk Kuantan merupakan rumah sakit tipe $\mathrm{C}$ milik pemerintah daerah kabupaten Kuantan Singingi. Jumlah tenaga keperawatan yang ada di RSUD Teluk Kuantan adalah sebanyak 120 orang. Dari survei awal yang dilakukan oleh peneliti terhadap 15 orang perawat yang ada di RSUD Teluk Kuantan dengan menggunakan kuesioner Nordic Body Map, diketahui bahwa sebanyak 85\% perawat memiliki keluhan musculoskeletal dengan rincian keluhan: punggung 55\%, bahu $45 \%$, leher $65 \%$ dan pergelangan tangan $60 \%$. Dari hasil survei awal yang dilakukan oleh Dimana tingkat keluhan 
yang sangat nyeri terdapat pada bagian pinggang dan bahu perawat. Dari pengamatan yang dilakukan, diketahui bahwa banyak postur kerja yang tidak ergonomis yang dilakukan oleh perawat saat melakukan pekerjaannya, seperti mengangakat pasien dari kursi roda ke tempat tidur pasien, dengan posisi tubuh membungkuk, punggung memuntir, leher menunduk.

Berdasarkan latar belakang yang dipaparkan di atas, maka peneliti tertarik untuk melakukan penelitian mengenai “ Hubungan Angkat Angkut Pasien Dengan Keluhan Musculoskeletal Disorders (MSD's) Pada Perawat Ruang Rawat Inap RSUD Teluk Kuantan Tahun 2018”.

\section{METODE}

Jenis penelitian ini adalah Kuantitatif Analitik Observasional dengan desain Analytical Cross-sectional Study yang dilaksanakan di RSUD Teluk Kuantan, yang dilakukan pada bulan JuniJuli 2018. Populasi dalam penelitian ini adalah perawat ruang rawat inap (umum, bedah, dan VIP) yang berjumlah 56 orang. Sampel yang digunakan adalah total populasi perawat ruang rawat inap yaitu 56 responden. Pengumpulan data keluhan musculoskeletal disorders dilakukan dengan instrumen kuesioner nordic body map yaitu pemeriksaan keluhan pada 28 titik tubuh responden berdasarkan peta tubuh dengan melakukan penilaian 4 tingkat keluhan responden (0.1.2 dan 3), instrumen pengumpulan data variabel postur kerja menggunakan REBA worksheet, dan instrumen pengumpulan data variabel berat beban, umur, indeks massa tubuh, kebiasaan olahraga, dan masa kerja adalah kuesioner. Data yang dikumpulkan adalah data primer dari semua variabel variabel independen. Analisis bivariat dilakukan dengan uji ChiSquare dan untuk analisis Multivariat dilakukan dengan uji Regresi Logistik Ganda.

\section{HASIL}

Proporsi keluhan musculoskeletal disorders pada perawat ruang rawat inap RSUD Teluk Kuantan dipeoleh sebesar $66,1 \%$. Mayoritas perawat mengalami keluhan pada bagian pinggang, bahu, dan leher. Keluhan terendah yaitu 0 (tidak sakit) dan keluhan tertinggi yaitu 3 (sangat sakit).

Hasil uji bivariat terhadap 6 variabel, terdapat 3 variabel yang mempunyai hubungan signifikan dengan keluhan musculoskeletal disorders yaitu postur kerja (pvalue = 0,001), umur (pvalue $=0,006)$, dan masa kerja (pvalue $=0,000)$. Berdasarkan nilai POR maka perawat yang melakukan angkat angkut pasien dengan postur kerja risiko tinggi berisiko mengalami keluhan musculoskeletal disorders 7 kali bila dibandingkan dengan perawat yang bekerja dengan postur kerja risiko rendah. Perawat dengan umur $\geq 35$ tahun berisiko mengalami keluhan musculoskeletal disorders 5 kali bila dibandingkan dengan perawat yang berusia $<35$ tahun. Perawat dengan masa kerja $\geq 5$ tahun berisiko mengalami keluhan musculoskeletal disorders 16 kali bila dibandingkan dengan perawat dengan masa kerja $<5$ tahun (Tabel 1). 
Tabel 1 Hubungan Variabel independen dengan keluhan muscloskeletal disorders pada perawat ruang rawat inap RSUD Teluk Kuantan Tahun 2018

\begin{tabular}{|c|c|c|c|c|c|}
\hline \multirow[t]{3}{*}{ Variabel } & \multicolumn{3}{|c|}{ Keluhan MSD's } & \multirow{3}{*}{$\begin{array}{c}\mathrm{P} \\
\text { value }\end{array}$} & \multirow{3}{*}{$\begin{array}{c}\text { POR } \\
(95 \% \mathrm{CI})\end{array}$} \\
\hline & Ada keluhan & $\begin{array}{c}\text { Tidak ada } \\
\text { keluhan }\end{array}$ & Total & & \\
\hline & $\mathrm{n}=37(\%)$ & $\mathrm{n}=19(\%)$ & $\mathrm{n}=56(\%)$ & & \\
\hline \multicolumn{6}{|l|}{$\begin{array}{c}\text { Postur } \\
\text { kerja }\end{array}$} \\
\hline $\begin{array}{l}\text { Risiko } \\
\text { tinggi }\end{array}$ & $31(79,5)$ & $8(20,5)$ & $39(100)$ & 0,001 & 7,104 \\
\hline $\begin{array}{l}\text { Risiko } \\
\text { rendah }\end{array}$ & $6(35,3)$ & $11(64,7)$ & $17(100)$ & & $\begin{array}{l}(2,010- \\
25,105)\end{array}$ \\
\hline \multicolumn{6}{|l|}{$\begin{array}{l}\text { Berat } \\
\text { beban }\end{array}$} \\
\hline Berisiko & $21(60,0)$ & $14(40,0)$ & $35(100)$ & 0,215 & 0,469 \\
\hline $\begin{array}{c}\text { Tidak } \\
\text { berisiko }\end{array}$ & $16(76,2)$ & $5(23,8)$ & $21(100)$ & & $\begin{array}{c}(0,140- \\
1,573)\end{array}$ \\
\hline \multicolumn{6}{|l|}{ Umur } \\
\hline Berisiko & $24(82,8)$ & $5(17,2)$ & $29(100)$ & 0,006 & 5,169 \\
\hline $\begin{array}{c}\text { Tidak } \\
\text { berisiko }\end{array}$ & $13(48,1)$ & $14(51,9)$ & $27(100)$ & & $\begin{array}{l}(1,520- \\
17,580)\end{array}$ \\
\hline IMT & & & & & \\
\hline $\begin{array}{c}\text { IMT } \\
\text { berlebih }\end{array}$ & $21(70,0)$ & $9(30,0)$ & $30(100)$ & 0,505 & 1,458 \\
\hline IMT normal & $16(61,5)$ & $10(38,5)$ & $26(100)$ & & $\begin{array}{c}(0,480- \\
4,429)\end{array}$ \\
\hline \multicolumn{6}{|l|}{$\begin{array}{c}\text { Kebiasaan } \\
\text { olahraga }\end{array}$} \\
\hline Kurang & $19(61,3)$ & $12(38,7)$ & $31(100)$ & 0,400 & 0,616 \\
\hline Cukup & $18(72,0)$ & $7(28,0)$ & $25(100)$ & & $\begin{array}{c}(0,198- \\
1,913)\end{array}$ \\
\hline \multicolumn{6}{|l|}{ Masa kerja } \\
\hline Berisiko & $35(77,8)$ & $10(22,2)$ & $45(100)$ & 0,000 & 15,750 \\
\hline $\begin{array}{c}\text { Tidak } \\
\text { berisiko }\end{array}$ & $2(18,2)$ & $9(81,8)$ & $9(100)$ & & $\begin{array}{l}(2,919- \\
84,987)\end{array}$ \\
\hline
\end{tabular}

\section{Sumber : Analisis Data Primer}

Hasil analisis multivariat dengan 3 kali pemodelan menunjukkan bahwa variabel yang berhubungan secara bermakna dengan keluhan musculoskeletal disorders adalah postur kerja dan masa kerja. Variabel umur dalam angkat angkut pasien variabel confounding terhadap postur kerja dan masa kerja, dan variabel 
berat beban dalam angkat angkut pasien merupakan variabel confounding terhadap variabel postur kerja dan masa kerja. Hasil analisis didapatkan bahwa variabel yang paling dominan berhubungan dengan keluhan musculoskeletal disorders dengan nilai $\mathrm{POR}=17,949$.

Tabel 2 Pemodelan Multivariat Akhir

\begin{tabular}{llcccc}
\hline No & Variabel & P value & POR & \multicolumn{2}{c}{ 95\% CI for Exp (B) } \\
& & & & Lower & Upper \\
\hline 1 & Postur kerja & 0,013 & 7,646 & 1,542 & 37,909 \\
2 & Berat beban* & 0,160 & 0,316 & 0,063 & 1,576 \\
3 & Umur* & 0,328 & 2,160 & 0,462 & 10,095 \\
4 & Masa kerja & 0,007 & 17,949 & 2.212 & 145,619 \\
\hline
\end{tabular}

Nagelkerke $R$ Square $=0,511$

Omnibus test: $<0,001$

*variabel confounding

\section{PEMBAHASAN}

\section{Gambaran Keluhan Musculoskeletal Disorders}

Berdasarkan hasil penelitian yang dilakukan, didapatkan hasil bahwa $66,1 \%$ perawat mengalami keluhan MSD's. berdasarkan grafik 1 diketahui bahwa mayoritas perawat mengalami keluhan di bagian pinggang 32 orang, bahu kanan 28 orang, leher 25 orang, dan betis kanan 24 orang.

Berdasarkan study European Survey on Working Condition (ESWC), MSD's yang dirasakan pekerja kebanyakan dirasakan pada tubuh bagian leher, piggang, serta otot-otot rangka bagian atas. Keluhan pada pinggang serta anggota tubuh bagian atas disebabkan karena adanya pekerjaan dengan posisi yang tidak alamiah yang dilakukan secara berulang-ulang, mengangkat beban yang berat serta postur tubuh yang tidak dapat menyesuaikan dengan posisi objek yang dikerjakan, sehingga pekerja tidak terlalu memperhatikan posisi kerja yang ergonomis (European Agency For Safety And Health at Work, 2010).
Hasil pengamatan di tempat penelitian, menunjukkan bahwa keluhan yang dirasakan kemungkinan juga disebabkan karena sarana yang ada di rumah sakit, yang mana ruang rawat inap RSUD Teluk Kuantan untuk yang kelas III terdapat 6 pasien di dalam satu ruangan, dan juga di dalam ruangan tersebut juga ada keluarga pasien yang menunggu pasien, hal ini bisa berdampak kepada sulitnya aktivitas mengangkat dan memindahkan pasien.

Untuk tempat tidur atau brankar pasien masih menggunakan jenis tempat tidur yang manual, sehingga untuk ketinggiannya tidak dapat disesuaikan dengan postur tubuh perawat, hal ini dapat berdampak pada timbulnya keluhan musculoskeletal disorders. Oleh karena itu pengendalian bisa dilakukan oleh manajemen dengan cara perubahan metode kerja, menata ulang atau re-design ruangan perawatan untuk mengurangi risiko MSD's, libatkan perawat untuk memberikan ide-ide yang membuat mereka nyaman dalam bekerja, sehingga produktivitas kerja dapat meningkat. 
Kondisi lainnya yaitu area kerja terkait dengan kondisi fisik akses jalan bagi para pasien maupun perawat dari lantai 1 ke lantai 2 tidak menggunakan lift, namun secara manual yaitu tangga atau ram, sehingga para perawat perlu mengerahkan tenaga yang lebih saat melakukan mobilisasi pasien, seperti mendorong ataupun menahan bed / kursi roda pasien.

\section{Variabel \\ Independen \\ Berhubungan dengan \\ Musculoskeletal Disorders \\ Postur Kerja}

Dalam penelitian ini postur kerja angkat angkut pasien berhubungan sebab akibat dengan keluhan musculoskeletal disorders pada perawat ruang rawat inap. Perawat dengan postur kerja risiko tinggi (REBA 8-15) maka berisiko 8 kali lebih besar mengalami keluhan musculoskeletal disorders dibandingkan dengan perawat dengan postur kerja risiko rendah (REBA 1-7). Perawat yang paling banyak mengalami musculoskeletal disorders pada risiko penanganan pasien, keadaan tersebut dapat terjadi akibat kegiatan penanganan pasien seperti mengangkat, mendorong, menarik dan menurunkan dalam postur kerja yang tidak ergonomis (Maysyaroh, 2016). Postur kerja yang tidak benar dapat menyebabkan posisi bagian tubuh bergerak menjauhi posisi alamiahnya, misalnya pergerakan tangan terangkat, punggung yang terlalu membungkuk, kepala terangkat, dan leher yang berputar. Semakin jauh suatu bagian tubuh seseorang dari pusat gravitasi tubuh, maka semakin tinggi pula risiko terjadinya keluhan sistem muskuloskeletal. Postur kerja yang tidak benar dan terlalu dipaksakan akan berdampak pada kelelahan otot sehingga kerja menjadi tidak efisien, dalam jangka waktu lama akan menyebabkan punggung (Nurmianto, 2008). Untuk mengurangi terjadinya keluhan musculoskeletal pada perawat, maka perawat perlu diberikan pelatihan khusus tentang penanganan pasien yang ergonomis. Perawat tidak perlu berusaha untuk mengangkat pasien bila tidak diperlukan sekali ataupun kalau bisa diusahakan mengangkat pasien minimal dilakukan 2 orang perawat.

\section{Masa Kerja}

Dalam penelitian ini masa kerja dalam angkat angkut pasien berhubungan sebab akibat dengan keluhan musculoskeletal disorders pada perawat ruang rawat inap. perawat dengan masa kerja $\geq 5$ tahun berisiko 18 kali mengalami keluhan musculoskeletal disorders dibandingkan dengan perawat yang masa kerjanya $<5$ tahun. Masa kerja adalah hasil akumulasi dari aktivitas kerja yang dilakukan seseorang dalam jangka waktu yang panjang. Apabila aktivitas tersebut dilakukan terus-menerus akan mengakibatkan gangguan pada tubuh. Hal ini didukung penelitian yang dilakukan Boshuizen (2009), masa kerja yang lebih dari 5 tahun lebih berisiko terkena nyeri punggung dibandingkan dengan responden dengan masa kerja $<5$ tahun. Karena semakin lama masa bekerja seseorang akan mempengaruhi keluhan pada sistem otot juga dikarenakan beban statis yang terus menerus. Hasil penelitia ini sejalan dengan penelitian Taufik dkk (2017) pada perawat RSU Sari Mutira Medan. Hasil tersebut menemukan adanya hubungan masa kerja dengan keluhan musculoskeletal disorders. Dari hasil analisa dan teori di atas dapat disimpulkan bahwa keluhan musculoskeletal disorders pada perawat akan dipengaruhi oleh masa 
kerja perawat tersebut. Semakin lama nekerja maka akan semakin berisiko perawat tersebut mengalami keluhan musculoskeletal disorders.

Variabel Independen yang Tidak Berhubungan dengan Keluhan Musculoskeletal Disorders Indeks Massa Tubuh

Hasil penelitian ini menunjukkan indeks massa tubuh tidak berhubungan dengan keluhan musculoskeletal disorders, hal ini mungkin terjadi karena adanya bias informasi, dimana untuk berat badan dilakukan pengukuran melalui penimbangan, tetapi ada beberapa responden yang hanya berdasarkan secara wawancara saja dan mungkin didapatkan beberapa hasil yang tidak valid terhadap berat badan responden. Hasil penelitian ini juga sesuai dengan teori yang menyatakan bahwa berat badan, tinggi badan dan massa tubuh juga memiliki pengaruh yang relatif kecil terhadap terjadinya keluhan otot skeletal (Tarwaka, 2015). Kemungkinan lain penyebab tidak adanya hubungan IMT dengan keluhan musculoskeletal disorders adalah karena jumlah sampel yang kecil.

\section{Kebiasaan Olahraga}

Hasil penelitian menunjukkan bahwa variabel kebiasaan olahraga tidak berhubungan dengan keluhan musculoskeletal disorders. Hasil penelitian ini juga didukung dengan hasil penelitian yang dilakukan Puspita Dewi dkk (2015), dimana dari hasil uji statistik didapatkan $p$ value $(0,456>0,05)$ yang artinya tidak ada hubungan yang bermakna antara kebiasaan olahraga dengan keluhan MSD's. Hal ini juga didukung dengan teori yang mana pada umumnya, keluhan otot jarang ditemukan pada seseorang yang dalam kegiatan kesehariannya mempunyai waktu istirahat yang cukup. Meskipun pada penelitian ini tidak didapatkan hubungan antara kebiasaan olahraga terhadap keluhan musculoskeletal disorders sebaiknya juga perawat tetap menjaga kesegaran jasmaninya dengan melakukan exercise minimal satu kali dalam seminggu atau stretching atau peregangan otot ringan setiap 2 jam sekali selama 2-3 menit. Kemungkinan untuk variabel ini perlu untuk dilakukan penelitian yang lebih lanjut.

\section{KESIMPULAN}

Proporsi perawat yang mengalami keluhan musculoskeletal disorders adalah $66,1 \%$, dengan mayoritas keluhan pada bagian tubuh pinggang, bahu kanan dan leher. Variabel yang mempunyai hubungan sebab akibat dengan keluhan musculoskeletal disorders adalah postur kerja dan masa kerja. Variabel confounding yaitu berat beban dan umur . Variabel yang tidak berhubungan dengan keluhan musculoskeletal disorders adalah indeks massa tubuh dan kebiasaan olahraga.

\section{SARAN}

Disarankan kepada perawat untuk memperhatikan cara mengangkat pasien yang benar, yaitu dengan cara mengurangi posisi tubuh dalam keadaan terlalu membungkuk, dan kedua kaki harus dalam keadaan ditekuk tidak lurus, usahakan memegang pasien dekat dengan tubuh sambil mengangkat untuk mempertahankan pusat gravitasi tubuh dan tetap stabil di kaki, tekuk dan angkat dengan lutut, bukan dengan pinggang. Disarankan agar peran komite K3RS harus lebih aktif untuk pencegahan keluhan musculoskeletal disorders dengan 
melakukan pelatihan tentang penangangan pasien yang ergonomis, sehingga perawat mempunyai bekal pengetahuan dan keterampilan yang berhubungan dengan pekerjaannya, dan hendaknya dilakukan secara kontinyu agar menjadi kebiasaan dalam melakukan penanganan pasien terutama angkat dan angkut pasien. Untuk penelitian lebih lanjut, disarankan untuk meneliti variabel lainnya yang belum diteliti pada penelitian ini, seperti status kesehatan dan nutrisi, suhu dan udara.

\section{DAFTAR PUSTAKA}

As'adi, A. Musthofa. Sujoso, A. Prahastuti., Prasetyowati, I. (2014). Hubungan Antara Karakteristik Individu Dan Manual Material Handling Dengan Keluhan Muskuloskeletal Akibat Kerja. EJurnal Pustaka Kesehatan. Vol. 2 (No.2).

Budiono, Sugeng AM., Jusuf, R.M.S., Pusparini, Adriana. (2005). Bunga Rampai Hiperkes \& KK. Semarang: Badan Penerbit Universitas Diponegoro.

European Agency For Safety and Health at Work. 2010. European Risk Observatory Report. Luxembourg: Publications Office of the European Union Available at https://osha.europa.eu/en/tools-and publications/publications/reports/TE RO09009ENC

ILO. (2013). The Prevention of Occupational Diseases, (online). Diakses dari: http://www.ilo.org/wcmsp5/groups/p ublic/@ed_protect/@protrav/@safe work/documents/publication/wcms_ 208226.pdf.
Kurniawidjaja, Meily. Purnomo, Edi. Maretti, Nadia. Pujriani, Ike. (2014). Pengendalian Risiko Ergonomic Kasus Low Back Pain Pada Perawat Di Rumah Sakit. Jurnal Kesehatan Mayarakat UI, Vol. 46, (No.4) , Pusat Kajian dan Terapan Keselamatan dan Kesehatan Kerja FKM UI.

Maysyaroh, N. Dessy. (2016). Hubungan Patient Handling Dengan Kejadian Musculoskeletal Disorders Pada Perawat di RSU PKU Muhammadiyah Delanggu. 6Desember-2016.

Nurmianto, Eko. (2008). Ergonomi Konsep Dasar dan Aplikasinya. Surabaya: Guna Widya.

Nuryaningtyas, B. Maghfiroh, dan Martiana, T. (2014). Analisis Tingkat Risiko Muskuloskeletal Disorders (MSDs) Dengan Rapid Upper Limbs Assessment (RULA) Dan Karakteristik Individu Terhadap Keluhan MSDs. The Indonesian Journal of Occupational Safety and Health Author (IJOSH). Vol 3, (No.2)

OSHA 3182. (2013). Ergonomics: The Study of Work, U.S: Departement of Labour.

Puspita Dewi, A. Kurnia., Tarwaka, dan Astuti, D. (2015). Hubungan Tingkat Risiko Postur Kerja Dan Karakteristik Individu Dengan Tingkat Risiko Keluhan Low Back Pain Pada Perawat Bangsal Kelas III di Rumah Sakit PKU Muhammadiyah Surakarta. Artikel Publikasi Ilmiah. 
Rossa, G. Ulya., Helmi, Z. Noor., Setyaningrum, R., Marlinae, L., Rosadi, D. (2017). Hubungan Faktor Individu Dan Faktor Pekerjaan Dengan Keluhan Musculoskeletal Disorders (MSDs) Pada Perawat. Jurnal Keselamatan dan Kesehatan Kerja.

Saftarina, F., dan Simanjuntak, D. Loria. (2017). Postur Kerja Dan Keluhan Musculoskeletal Disorders Pada Perawat di Instlasi Rawat Inap RSUD Abdul Moeloek. Jurnal Kedokteran UNILA, Vol. 1, (No. 3).
Tarwaka. (2015). Ergonomi Industri : Dasar-Dasar Pengetahuan Ergonomi dan Aplikasi di Tempat Kerja. Solo: Harapan Press Solo. Revisi Edisi: 2.

Taufik, R. Ketaren, O., Salmah, dan M. Sidan Umi. (2017). Faktor-Faktor Yang Berpengaruh Terhadap Musculoskeletal Disorders Pada Perawat Di Rumah Sakit Umum Sari Mutiara Medan Tahun 2017. Jurnal Riset Hesti Medan, Vol.3, (No.1). 